\title{
THE Genesis of SAMUELSON AND SOLOW'S PRICE-INFLATION \\ PHILLIPS CURVE
}

\author{
BY KEVIN D. HOOVER
}

CHOPE WORKING PAPER NO. $2014-10$

REVISED 7 JULY 2014

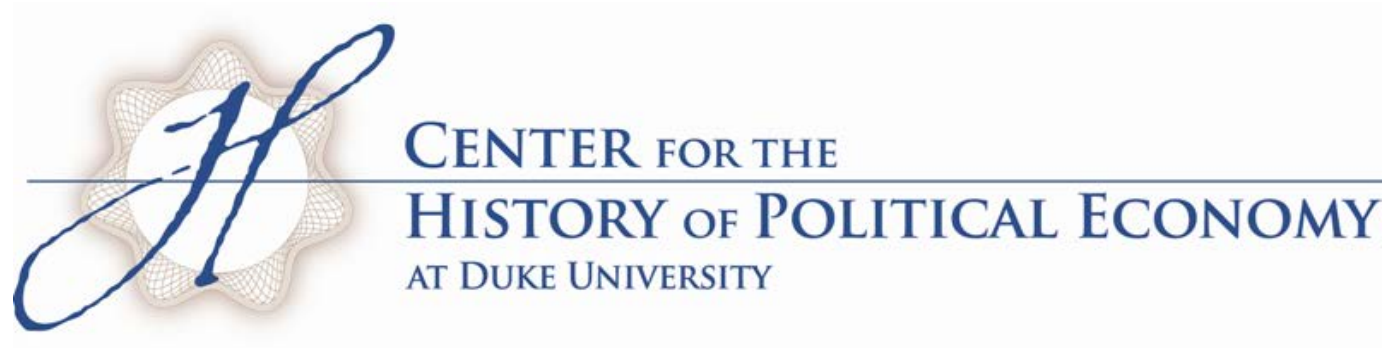




\title{
The Genesis of Samuelson and Solow's Price-Inflation Phillips Curve*
}

\author{
Kevin D. Hoover \\ Department of Economics \\ Department of Philosophy \\ Duke University
}

Revised, 1 July 2014

*I thank Thomas Hall and William Hart for providing me with their data, and Robert Solow, Roger Backhouse, James Forder, Robert Dimand, and Humberto Barreto for comments on an earlier draft. 


\section{Abstract}

\section{of}

\section{The Genesis of Samuelson and Solow's Price-Inflation Phillips Curve}

Samuelson and Solow in their 1960 paper in the American Economic Review: Papers and Proceedings were among the first economists to engage with Phillips' famous unemployment/wage-inflation analysis, now referred to as the Phillips curve. They addressed the question of the relevance of Phillips's analysis for the United Kingdom to the United States, and in process formulated the first unemployment/price-inflation version of the Phillips curve and were the first to interpret the Phillips curve as a menu for policy. Their paper was an informal analysis presented at a conference. The current paper offers a careful reconstruction and assessment of their original formulation, documenting the close relationship between the wage-inflation and price-inflation versions of the Phillips curve. A recent paper of Hall and Hart (2012) that suggests, first, that Samuelson and Solow should have reached different conclusions about the price-Phillips curve on the basis of regression estimates of their own data and, second, that had they done so the "inflationist" course of U.S. macroeconomic policy in the 1960s and 1970s would have been different. With the reconstruction as a background, the current paper demonstrates that Hall and Hart have not grasped the key details of Samuelson and Solow's analysis, and that they ignore the actual context of the paper, so that neither of their suggestions is likely: Samuelson and Solow would have no reason to reach any different conclusion based on Hall and Hart's estimates, and the course of macroeconomic policy is unlikely to have been affected in any case.

Keywords: Phillips curve, Paul A. Samuelson, Robert M. Solow, inflation, unemployment, macroeconomic policy

JEL Codes: B22, B23, B31, E31, E61, E63 


\section{The Genesis of Samuelson and Solow's Price-Inflation Phillips Curve}

In an historian we are not to be critical for every punctilio, not relating to his main design; yet I think 'tis but just to demand that what he doth write be true.

HENRY STUBBS, “The Lord Bacon’s Relation of the Sweating Sickness Examined” (1671)

In 1958, A.W.H. Phillips published his famous study in which found a surprisingly consistent, nonlinear, inverse relationship between unemployment and wage inflation in the United Kingdom over nearly a century. The relationship, which, to be sure, had antecedents, was soon dubbed the "Phillips curve" and has been a fixture of macroeconomics ever since. Although Phillips’s original curve related unemployment to wage inflation, most Phillips curves relate unemployment to price inflation (or the change in the rate of price inflation). That practice appears to have originated in Samuelson and Solow’s paper “Analytical Aspects of Anti-inflation Policy” (1960), which made the suggestion that - at least in the short run - the Phillips curve might be regarded as a menu monetary and fiscal policymakers of feasible combinations of unemployment rates and inflation. A recent paper by Hall and Hart (2012) that revisits Samuelson and Solow's price-Phillips curve has prompted a good deal of discussion on the Societies for the History of Economics (SHOE) listserv. Hall and Hart maintain that Samuelson and Solow's Phillips curve was essential to imparting an inflationist bias to U.S. monetary and fiscal policy in the 1960s. But they conclude, econometric estimations of the Phillips curve estimations that Samuelson and Solow could have undertaken, but did not in fact undertake would not have resulted in anything like the price-Phillips curve that is presented as Figure 2 in their paper (and reproduced as Hart and Hall’s Figure 1): “The empirical results presented in [our] paper challenge the results as well as the policy implications of the Samuelson-Solow Phillips curve” (Hart and Hall 2012, p. 67). Hart and Hall’s conclusions, I believe, rest on a 
misinterpretation of Samuelson and Solow's Phillips curve and the way in which they quantified it. My claim is best supported through a detailed reconstruction of the formulation of the pricePhillips curve.

\section{The Analysis of Wages and Prices}

The context of Samuelson and Solow's paper is essential to understanding their Phillips curve. ${ }^{1}$ Unlike Phillips's own paper, Samuelson and Solow were not engaged in a refined quantitative investigation. Their paper was not a report on detailed research, but part of an attempt to clarify various issues surrounding the large literature that had developed in the 1940s and 1950s - to which Phillips’s paper was a signal contribution - concerning the diagnosis and control of inflation. It was written for oral presentation at the meetings of the American Economic Association in late December 1959, and was published in the Papers and Proceedings number of the American Economic Review in May 1960. Its tone is conversational and exploratory. Distinguishing types of inflation (e.g., cost-push versus demand-pull) and possible causal mechanisms (e.g., monetary expansion as in the classic quantity theory versus excess aggregate demand in the manner of Keynes (1936)) are central concerns. Phillips is first mentioned a little more than half way into the eighteen-page paper: "His findings are remarkable, even if one disagrees with his interpretations” (p. 186). The striking thing about Phillips's findings was the consistency of the relationship in the United Kingdom between unemployment and wage inflation before World War I and after World War II. No equally detailed study, they say, had been conducted for the United States, but preliminary evidence suggested that it might take fairly high levels of unemployment to stabilize wage inflation. What would a detailed study show? Samuelson and Solow (p. 187) wrote: "There may be no such relation for this country. If there

\footnotetext{
${ }^{1}$ Forder (2010a) gives a valuable discussion of the context of Samuelson and Solow's paper.
} 
is," many questions would be raised, such as, "why does it not seem to have the same degree of long-run invariance as Phillips’ curve for the U.K.?” And they conclude, “Clearly a careful study of this problem might pay handsome dividends.” The second half of their paper is best seen as a preliminary scouting expedition for such a study.

The expedition begins in Section III with “A Closer Look at the American Data” (p. 187) - a look that takes the form of a scatter diagram (their Figure 1) of unemployment and wage inflation from about 1890 through $1959 .^{2}$ Figure 1 of the current paper is a scatterplot of the same data that Samuelson and Solow display in their own Figure 1 (see the Appendix). They remark that "A first look at the scatter is discouraging; there are points all over the place” (p. 188). But that is not a surprise; for, as we have seen, they were predisposed to believe that the American data did not display any simple stable relationship. Their discussion proceeds by noting both the instabilities and the underlying systematic effects.

Samuelson and Solow do not draw crisp boundaries, but in effect they divide the data into four distinct groups of data:

- Early 20th Century (1901-1914; 1919-1929): “the bulk of the observations - the period between the turn of the century and the first war, the decade between the end of that war and the Great Depression, and the most recent ten or twelve years - all show a rather consistent pattern. Wage rates do tend to rise when the labor market is tight, and the tighter the faster” (p. 189). The regression line for the Early 20th Century data in our Figure 1 clearly indicates the negative relationship. The post-World War II period is not counted as part of this group, since Samuelson and Solow note that "the relation, such as it is, has shifted upward slightly but noticeably in the forties and fifties” - a fact confirmed by the regression line for the Postwar data in our Figure 1.

\footnotetext{
${ }^{2}$ The sources, definitions, and coverage dates of the data are discussed in the Appendix.
} 
- Depression (1933-1939): the Depression, of course, started in 1929 (hence one segment of the Early 20th Century data stops in that year); but Samuelson and Solow observe that “1933 to 1941 appear to be sui generis: money wages rose or failed to fall in the face of massive unemployment” (p. 188). The reason for the distinctiveness of the period, they argue, is either "the workings of the New Deal” (p. 188) or that "by 1933 much of the unemployment had become structural, insulated from the functioning labor market, so that in effect the vertical axis ought to be moved over to the right” (p. 189). The regression line for the Depression confirms these observations: it is flatter (a weaker relationship between the unemployment rate and the rate of wage inflation) and shifted rightward.

- Postwar (1946-1959): “from 1946 to the present, the pattern is fairly consistent and consistently different from the earlier period [i.e., our Early 20th Century period] ...” (p. 189).

- Other (1890-1900; 1915-1918; 1930-1932; 1942-1945): this is the residual category including all years not otherwise grouped in Samuelson and Solow's discussion. The regression line for the Other period shows an inverse relationship not very different from the Early 20th Century and Postwar periods, which highlights Samuelson and Solow’s claim that the Depression is sui generis.

Samuelson and Solow do not draw a wage curve in the manner of Phillips, but they take one as implicit, summarizing the distinct behaviors of the different data groups as "[t]he apparent shift of our Phillips curve ...” (p. 189). And they describe its salient features; referring to the Early 20th Century group, they write “Manufacturing wages seem to stabilize absolutely when 4 to 5 percent of the labor force is unemployed; and wage increases equal to the productivity 
increase of 2 to 3 percent per year is the normal pattern at about 3 per cent unemployment”; while noting that in the Postwar period "it would take more like 8 percent unemployment to keep money wages from rising. And they would rise at 2 to 3 percent per year with 5 or 6 per cent of the labor force unemployed” (p. 189). These characterizations are impressionistic, but they do comport - more or less - with the regressions lines in Figure 1: for the Early 20th Century group a 31/2 percent unemployment rate corresponds to about a 21/2 percent rate of wage growth, and a 6 percent unemployment rate corresponds to a zero rate of wage growth; while for the Postwar period, a 51/2 percent unemployment rate corresponds to a $2 \frac{1}{2} 2$ rate of wage growth, and an 8 percent unemployment rate corresponds to a zero percent rate of wage growth. One should, however, not take the linear regression lines too seriously:

The English data show a quite clearly nonlinear (hyperbolic) relation between wage changes and unemployment, reflecting the much discussed downward inflexibility. Our American figures do not contradict this, although they do not tell as plain a story as the English. [Samuelson and Solow 1960, p. 190]

\section{The Price-Phillips Curve}

The importance that Samuelson and Solow attach to that rate of unemployment that corresponds to 2 to 3 percent wage growth arises from the fact that a firm that increases its wage rates at the same rate as its rate of growth of labor productivity will not experience rising labor costs per unit and, therefore, will not feel any cost pressure to raise prices. ${ }^{3}$ This relationship is the key to the construction of the price-Phillips curve; for the curve in their Figure 2 is simply a mapping of the

\footnotetext{
${ }^{3}$ With a Cobb-Douglas production function and perfect competition, the equilibrium real wage equals the labor share in output $(\alpha)$ times the average product of labor $(Y / L)$, which is the rate of labor productivity $(\theta)$ : $w / p=\alpha(Y / L)=\alpha \theta$. Translated into growth rates (indicated by tildes over variables), this becomes $\tilde{w}-\tilde{p}=\tilde{\alpha}+\tilde{\theta} \approx \tilde{\theta}$, since the labor share is approximately constant. Thus, when the growth of wages equals productivity growth ( $\tilde{w} \approx \tilde{\theta})$, inflation is zero ( $\tilde{p}=0$ ). Solow (2014) notes that the translation from wage- to price-inflation described here was the common practice at the time in large-scale macroeconometric models, which took unit labor costs as the key variable.
} 
key points of Samuelson and Solow’s impressionistic (not-drawn-but-described) wage-Phillips curve into unemployment/price-inflation space, using the relationship that the rate of price inflation equals the rate of wage inflation minus the rate of growth of labor productivity $(\tilde{p}=\tilde{w}-\tilde{\theta})$, where the tildes indicate growth rates.

Samuelson and Solow describe the price-Phillips curve in their Figure 2 as "roughly estimated” (p. 192). They clearly do not refer to regression estimates; for they conducted no regression analysis nor do they even present a scatterplot of unemployment and price-inflation data figure containing their their curve. They describe precisely what they mean by estimation when they say, “we translate the Phillips' diagram showing the American pattern of wage increases against degree of unemployment into a related diagram showing the different levels of unemployment that would be ‘needed’ for each degree of price level change,” and they underscore the rough nature of the exercise by referring to the key data involved in the translation as "guesses” (p. 192). Their curve is not constructed by fitting a line directly to unemployment/price inflation data. So, how was it constructed?

Samuelson and Solow stipulate 21/2 percent per year as “characteristic of our productivity growth” (p. 192). In round terms, this corresponds to their coarse characterization of 2 to 3 percent per year as a rate of wage growth that would not be associated with cost pressure, as well as to the actual average rate of productivity growth for the Postwar of 2.8 period percent per year, based on Rees’s (1959) data - the only dataset explicitly mentioned in their paper. In discussing the price-Phillips curve in their Figure 2, Samuelson and Solow refer to two points explicitly: point A corresponds to unemployment $U=5 \frac{1}{2}$ percent, $\tilde{p}=0$; point B corresponds to $U=3$ percent and $\tilde{p}=4.5$ percent per year (p. 192). 
Where do these figures come from? Point A corresponds to the translation from wageinflation to price-inflation space of Samuelson and Solow's characterization - noted previously of the Postwar period as displaying wage inflation of 2 to 3 percent per year when unemployment is 5 to 6 percent: $\tilde{p}=0=2.5-2.5=\tilde{w}-\tilde{\theta}$.

Samuelson and Solow give no explicit account of point B. Translated back into wageinflation space, it implies that $U=3$ percent, corresponds to $\tilde{w}=7.0=4.5+2.5=\tilde{p}+\tilde{\theta}$. This figure is consistent with Samuelson and Solow's characterization of the wage data at the coarse level of precision that they adopted throughout their discussion. For example, the regression lines for the Early 20th Century group lies very nearly parallel and 23/4 points below the regression line for the Postwar period. As already noted Samuelson and Solow see 3 percent unemployment as consistent with wage-inflation of 2 to 3 percent per annum in the Early 20th Century group. The upward shift implied by the regression lines would translate that into $U=3$ percent in the Postwar associated with $\tilde{w}=2.5+2.7=5.2$ percent per annum. That falls short of the implied value of $\widetilde{w}=7.0$, but then the estimate is based on linear regression curves, and Samuelson and Solow are clear that hyperbolic curves are appropriate, noting that wage rates rise the faster, the tighter the labor market. For the same, rightward translation a hyperbolic curve would imply a higher change in the rate of wage inflation than would a linear curve, presuming that the reason for the shift in the curve was an increase in the rate of unemployment for any given rate of wage inflation. Looking directly at the data, note that for the four points in the Postwar period lying in the interval $2.5 \leq U \leq 3.5$, the average value of $\widetilde{w}=8.0$, which is higher than the implied value of $\widetilde{w}=7.0$.

Two points are insufficient to determine a hyperbola. Samuelson and Solow do not name a third point; but, as we already observed, they do associate $U=8.0$ with $\widetilde{w}=0$ in the Postwar 
period. Let us call this point C. Translating into price-inflation space $\tilde{p}=-2.5=0-2.5=\tilde{w}-\tilde{\theta}$. If we assume that Samuelson and Solow fitted a hyperbola to these three points of same form as the one estimated by Phillips (1958, p. 290), the three points $A=(4.5,0), B=(3.0,4.5)$, and $C=$ $(8,-2.5)$ imply the curve in our Figure 2, corresponding to the equation:

$$
\tilde{p}=-32.2346+54.5451 \tilde{w}^{-0.2155} \text {. }
$$

Within the limits of measurements readily made with an ordinary ruler, Samuelson and Solow’s Figure 2 is not just a free-hand curve that passes through the named points A and B, but in fact corresponds everywhere to hyperbola described in equation (1) and in our Figure 1.

One lesson to be drawn from this exercise is that Samuelson and Solow's description of their price-Phillips curve in the legend of their Figure 1 as "roughly estimated" is perfectly apt. The curve corresponds very precisely to the three points that they single out as salient, but these points themselves are determined impressionistically. To some extent, their estimation method echoes that of Phillips. Phillips grouped his data into bins determined by six intervals of the unemployment rate. He then averaged the data for wage inflation within each bin and assigned the average value to the median point of the unemployment interval. It is to these six average data points that he fitted his hyperbola through a procedure that mixed least squares estimation and an informal adjustment of the intercept term (Phillips 1958, p. 290). This nonstandard procedure may have been motivated in part by the computational difficulties of implementing nonlinear regression in the 1950s, but Phillips is also clear that he used the averaging procedure to abstract from the cyclical properties of the data. Samuelson and Solow's procedure for determining the three salient points of their hyperbolic price-Phillips curve amounts to implicit averaging of the same sort. And the relationship of the annual data to the estimated curve is rather similar to the relationship noted by Phillips. Our Figure 2, shows that the data for the 
Postwar period form loops around the hyperbolic Phillips curve, with the beginning of each loop corresponding to the beginning of business-cycle expansions: the troughs of business cycles occurring in $19454^{\text {th }}$ quarter, 1949, $4^{\text {th }}$ quarter, $19542^{\text {nd }}$ quarter, and $19582^{\text {nd }}$ quarter. The first two loops run counterclockwise; while the third runs clockwise. Phillips (1958) had found counterclockwise loops for U.K. unemployment/wage-inflation data before World War I and clockwise loops after World War II.

A second lesson to be drawn from our reconstruction of Samuelson and Solow's procedure is that their curve is estimated for the postwar period. That fact poses an interpretive puzzle - one that I will argue trips up Hall and Hart: why if the curve is estimated on postwar data do Samuelson and Solow refer to it in the legend to their Figure 2 as "roughly estimated from the last 25 years of American data”? The most likely explanation is based in their view that the Depression is sui generis. Both the period before the Depression, excepting the years of World War I and those after World War II are referred to as following a "normal pattern” (p. 189), although the Postwar period is quantitatively distinct, though qualitatively similar, to what we have called the Early 20th Century group. The Depression period is characterized in their view by special factors (political or structural) affecting the labor market. Implicitly, Samuelson and Solow treat it as if it would have been similar to the Postwar period but for those special factors. And indeed, the key datum, the rate of productivity growth, is 2.80 percent per year for the period 1933-1957 and nearly identically 2.82 percent per year for 1946-1957.

Samuelson and Solow thus reject the unemployment-wage behavior of the Depression as informative about the Postwar period, when the special factors were not operative, but are happy to assert the similarity of the two periods in other respects. Their price-Phillips curve is, therefore, based on the unemployment/wage-inflation relationships of the Postwar period, and a 
rough characterization of the productivity data for both the Depression and the Postwar periods. It is meant to describe roughly what the relationship actually was in the Postwar period and what it would have been, but for special factors, in the Depression.

Whether or not this explanation is accepted, it would be hard to square Samuelson and Solow's actual construction of the price-Phillips curve with reference to the unemployment-wage behavior of the Depression. They clearly refer to facts that agree with the Postwar data. Equally, they clearly point out the massive rightward shift of the unemployment/wage-inflation data in the Depression. Given the way in which the price-Phillips curve is constructed from translating an implicit wage-Phillips curve by the rate of productivity growth, consistency would require a similar rightward shift of the price-Phillips curve: the same curve could not represent both periods, except in the counterfactual sense of representing how they would have been in the Depression barring special factors.

\section{Hall and Hart}

Hall and Hart (2012, pp. 65-66) estimate Phillips curves using rates of price inflation based on both the consumer price index (CPI) and the wholesale price index (WPI) of the form:

$$
\tilde{p}_{t}=b_{0}+b_{1}\left(1 / U_{t}\right)+b_{2}\left(1 / U_{t}^{2}\right)+\varepsilon_{t}
$$

where we have adopted our own tilde-notation to indicate rates of growth, the $\varepsilon$ indicates a stochastic error, and the $t$ subscripts index time. Their estimation period runs 1934-1958, which takes Samuelson and Solow's “last twenty-five years of American data” strictly, given their assumption that Samuelson and Solow’s data ends in 1958. (In the Appendix, I challenge that assumption, but it is not, I believe, consequential for either their results or for my reconstruction of the price-Phillips curve.) Their estimates yield an unemployment/price-inflation relationship 
that is upward-sloping over the range of 0 to 3 percent unemployment when based on the CPI

and over the range 0 to 4 percent unemployment when based on the WPI.

Hall and Hart pose two questions that they believe that their estimates raise:

First, would economic events during the 1960s and 1970s have turned out differently had Samuelson and Solow not weighed in with their Phillips curve? Second, would economic events have turned out differently had Samuelson and Solow presented an empirically estimated Phillips curve like the curves [that Hall and Hart estimate] . . . ? [Hall and Hart 2012, p. 67]

I will return to the first question presently. Meanwhile, consider the presupposition of the second question - namely, that Hall and Hart's estimates are ones that Samuelson and Solow should have made or - at the least - ones that economists in 1960 should have regarded as informative about the nature of the price-Phillips curve.

Hall and Hart's presupposition arises from a failure to grasp Samuelson and Solow’s analysis of the Phillips curve. Hall and Hart's failure is evident in their wavering between the view that Samuelson and Solow "estimated the relationship between the rate of inflation and the unemployment rate" (p. 63, their emphasis) and that they "never estimated their Phillips curve" (p. 62, abstract, my emphasis). ${ }^{4}$ Samuelson and Solow did estimate their curve, but they did not do so by the regression analysis of unemployment/price-inflation data. Rather they did it by translating points lying on an implicit wage-Phillips curve into unemployment/price-inflation space. ${ }^{5}$ Hall and Hart estimate curves for both CPI and WPI inflation, because in later

\footnotetext{
${ }^{4}$ They also quote Samuelson and Solow's legend to Figure 2 describing it as "roughly estimated" on p. 69, note 5. The claim that they never estimated the curve is repeated or implied (sometimes multiple times on the same page) on pp. 64, 67, and 68. The Samuelson-Solow price-Phillips curve is also referred to as "hand-drawn" on pp. 62, 64, 67, and 70. It is probably literally true that the curve was hand-drawn; for in 1960 virtually all published graphics would have been drawn by hand; but the implication is also that it was drawn free-hand, which given the precision with which Samuelson and Solow's curve conforms to equation (1) and our Figure 2 is unlikely. As we showed in Section II, Samuelson's and Solow's curve is precisely drawn on the basis of a somewhat stylized characterization of the unemployment/wage-inflation data.

${ }^{5}$ Solow (2014) recalls that they did not attempt regression analysis of the wage-inflation/unemployment data, because they were aware from the scatterplot that a bivariate regression would be inadequate, and Samuelson did not care for the kind of careful empirical analysis that would be needed to account for collinearity and simultaneity, and neither of them had the time to do it well in any case. Contemporaneous evidence confirms Solow's recollection: in
} 
recollections Solow was unclear about which series they used (p. 64). The internal evidence of Samuelson and Solow's paper, however, renders the question moot: Samuelson and Solow's method of estimation by translation did not require them to use any price series, since the rates of price inflation on the curve in their Figure 2 are simply the rates of wage inflation less the presumed productivity growth rate of 2.5 percent per year. Samuelson and Solow do not refer to a particular price series (neither to the CPI nor to the WPI) nor to its source, for the simple reason that they did not use a price series in estimating their curve. They do refer to a particular wage series, due to Rees (1959) (Samuelson and Solow 1960, p. 187).

The larger problem with Hart and Hall's approach is that they simply ignore Samuelson and Solow's detailed discussion of the wage-unemployment relationship. All they say about it (buried in an endnote) is that "[t]he backdrop to the Samuelson-Solow Phillips curve, and the only other diagram in their paper, was a scatter plot of the annual change in wages . .” (p. 69, note 6). Samuelson and Solow’s scatterplot may well be the "backdrop” to Samuelson and Solow's price-Phillips curve, but the analysis of the data of that scatterplot and the translation of that analysis into the unemployment/price-inflation space takes place on center stage: it is the very heart of the matter.

Once this point is understood, it is easy to see that Samuelson and Solow could not have consistently accepted anything like Hall and Hart's estimates. Hall and Hart run together three periods that Samuelson and Solow regard as distinct: the Depression, World War II (included in our Other group), and the Postwar period. Since Samuelson and Solow go out of their way to point out that the Depression period behaves like no other, and is both quantitatively and qualitatively massively different from the Postwar period, the same wage-Phillips curve could

a letter to Lipsey, Solow (1960) indicates that he contemplated a detailed empirical study along the lines of Lipsey's paper, but did not have sufficient time to do it. 
not fit both periods; and, if the same, wage-Phillips curve could not fit both periods, given their method of estimation by translation, ipso facto the same price-Phillips curve could not characterize both periods. The price-Phillips curve would have to reflect the shift in the underlying wage-Phillips curve.

The only reason to suppose that Samuelson and Solow could accept Hall and Hart's estimates is the statement in the legend to Samuelson and Solow's Figure 2 that the curve was "roughly estimated from the last twenty-five years of American data.” I have already offered a reasonable interpretation of this statement in Section II. Hall and Hart (p. 70) address Samuelson and Solow's statement in endnote 16 in which they reject the suggestion of a referee that Samuelson and Solow's curve is based on data for the thirteen postwar years corresponding to the data points "for recent years" that are circled on their unemployment/wage-inflation scatterplot (Figure 1). They reason, first, that were that so, then the reference in the legend would be an error; and, more than that, an error that no one in the vast literature on the Phillips curve had noticed. Of course, the possibility suggested by Section II is that the reference to twenty-five years is no error at all, but, nonetheless, one should not expect the actual data for the period from 1934 to 1945 to conform to the Samuelson and Solow's price-Phillips curve. The data for that period conforms only counterfactually: had the special circumstances, which Samuelson and Solow explicitly noted for the Depression and implicitly for World War II, not occurred, then the data would have conformed. It is the "normal" curve for the whole twentyfive years, not the actual curve.

It is possible to dig in one's heels and say, "twenty-five years is twenty-five years; the data must include the Depression and World War II or Samuelson and Solow must have made an error - end of story.” But consider the cost of that interpretive move. It implies that Samuelson 
and Solow thought that three distinct periods could be treated without any qualification as governed by the same Phillips curve. Yet, they have already rejected the stability of the wagePhillips curve relationship across those three periods; and, since their price-Phillips curve is a simple translation of the wage-Phillips curve by the trend rate of productivity growth, they could not consistently assert an unstable wage curve and a stable price curve. On the interpretive principle that we should minimize the attribution of inconsistency, either we should accept my interpretation that they use twenty-five years of productivity data and offer a counterfactual interpretation of the relevance of the curve to the earlier periods or, if one were to insist that an error has been made somewhere, that the error be in the assertion of a twenty-five-year estimation period - a relatively minor mistake - rather than in the assertion of an unstable wagePhillips curve, which has the absurd result of making utter nonsense of their discussion of unemployment and wage change, which is one of the major points of their analysis. ${ }^{6}$

Hall and Hart's second reason for rejecting the special status of the postwar data in Samuelson and Solow's estimates is that they take the referee to imply that the postwar estimates would not have had the hump-shape of the Phillips curve that they estimated for 1934-1958. They reëstimated equation (2) for the postwar period and still found a hump-shaped curve. But this raises the question of Hall and Hart's functional form. Their equation is quadratic in the inverse of the unemployment rate $(1 / U)$. It is this quadratic form that allows the curve to be hump shaped. They justify their functional form as the same form used by Lipsey (1960) in his follow up to Phillips's study of U.K. wage data. When they first drafted their paper, in 1959, Samuelson and Solow did not know Lipsey’s paper, which was not published until February 1960. This is hardly surprising; preprints or working papers were not as widely circulated in

\footnotetext{
${ }^{6}$ Solow (2014) himself suggests that the "twenty-five years” might have been the result of careless phraseology.
} 
those pre-internet days. ${ }^{7}$ We do know, however, that Samuelson and Solow did not have a quadratic function in mind, but rather a hyperbola, which cannot be hump shaped. To a degree, Hall and Hart's Phillips curve is hump shaped because of the a priori assumption of a quadratic form. Of course, we cannot say that the hyperbolic curve is automatically to be preferred to a quadratic curve, but simply finding the built-in hump shape within the range of positive unemployment rates does not, in itself, show the inferiority of the hyperbolic curve. And the acceptability of the hyperbolic curve cannot be tested within the framework of the quadratic curve, since it is not a special case of it.

We can, I believe, conclude that Samuelson and Solow would have rejected - indeed, should have rejected - Hall and Hart's estimates as not a sensible way to treat data that they knew were not stable. They would never have presented such estimates, so that Hall and Hart's second "what if" never gets off the ground. Yet, suppose that they had, what can we say about Hall and Hart’s first question: “would economic events during the 1960s and 1970s have turned out differently had Samuelson and Solow not weighed in with their Phillips curve?” Again, consider the presupposition of the question. Hall and Hart suppose that Samuelson and Solow's Phillips curve was directly and deeply influential with respect to economic policy in the 1960s and 1970s. This is, I believe, largely a myth (see Forder 2010a).

Hall and Hart's main support for the claim comes from two sources: a quotation from the Council of Economic Advisers in the Economic Report of the President (Kennedy 1962, p. 46; cited by Hall and Hart 2012, p. 64) that says that policy should aim to reduce unemployment without creating demand-induced inflation, and references to three papers by Robert Leeson

\footnotetext{
${ }^{7}$ Solow's (2014) confirms that he and Samuelson were ignorant of Lipsey's work when they first drafted their paper, a fact confirmed by Solow's (21 March 1960) letter to Lipsey requesting an offprint, which makes it clear that he had first read Lipsey's paper in the February 1960 number of Economica. A letter from Lipsey to Solow (30 March 1960) indicates that he was sending the offprint by separate cover.
} 
(1997a, 1997b, and 1997c). The statement of the President's Council was in 1962 by no means novel nor did it in any way require Samuelson and Solow's price-Phillips curve (or any other Phillips curve) for support. The idea that demand hitting a high level both reduced unemployment and risked higher inflation was an old one. It is found in Keynes's General Theory (1936), it formed the basis for discussions and quantifications of the "inflationary gap," which had been widespread in the 1940s and 1950s, and it was ubiquitous in the literature to which Samuelson and Solow directed the first half of their paper - before their discussion of the Phillips curve - to clarifying. Phillips (1958, esp. pp. 298-299), like Samuelson and Solow, was concerned to distinguish empirically between cost-push and demand-pull inflation, and, of course, the inverse relationship of aggregate demand and unemployment was widely accepted.

It would be easy to multiply examples of these ideas before Phillips or Samuelson and Solow’s papers, but one example will do:

Many of us know about the thesis of The Economist of London on the 'uneasy triangle'stable prices, full employment and strong economic pressure by organized labor, industry and agriculture” (Bronfenbrenner 1957, pp. 20-21). ${ }^{8}$

The report of the President's Council cited by Hall and Hart nowhere mentions the Phillips curve. It nowhere mentions the idea of a stable tradeoff between inflation and unemployment resulting in a menu for policy. Rather it points to the well-known situation of high levels of demand being both good for employment and bad for inflation - and it, tries to put a number on the sweet spot for unemployment. I do not mean to suggest that policy was not influenced by Samuelson and Solow’s analysis. That seems unlikely, given that Solow was a staff member of, and Samuelson a consultant to, the Council of Economic Advisers in 1962 (Kennedy 1962, p. 196). Surely, Samuelson and Solow drew on the range of their economic

\footnotetext{
${ }^{8}$ Even something like the Phillips curve itself might well have predated Phillips, see Fisher (1926), Humphrey $(1985,1986)$.
} 
insights in fulfilling their public duties. Instead, I am merely suggesting that the actual policies advocated, not only in 1962, but throughout the 1960s would hardly have been different, with or without Samuelson and Solow's price-Phillips curve (or, indeed, with or without Phillips's wagecurve), as long as it were dominated by American Keynesians of the stripe of Samuelson, Solow, James Tobin, Walter Heller, and Kermit Gordon - the last three being the actual members of the Council in 1962.

Hall and Hart also cite Leeson's papers in support of their thesis that the Samuelson and Solow's price-Phillips curve was critical for policymakers. But examination of those does not reveal any evidence that is more compelling the thin reed of the 1962 report of the Council of Economic Advisers.

The idea of the Phillips curve as dominating economic policy in the 1960s, appears to be largely a bit of Whig history, whose best-known proponent was Milton Friedman in his presidential address to the American Economic Association in 1967 (Friedman 1968). Before Friedman’s address and before the Phelps’s (1967) invention of the expectations-augmented Phillips curve, the Phillips curve received a moderate amount of academic attention. A search of economics articles in JSTOR for the term “Phillips curve” between 1958 and 1967 yields 50 articles using the term. A search of the period after Friedman's address, 1968 to the present yields 4,517 articles. ${ }^{9}$ The role of Friedman in the invention of the Phillips curve as a vastly influential policy tool has been discussed in great detail by James Forder (2010b; forthcoming).

There is little doubt that Samuelson and Solow saw the price-Phillips curve as a relationship that might be relevant to policy. The legend to their Figure 2 refers to a "menu." Hall and Hart (2012, p. 63, citing Leeson 1997b) interpret a later interview with Samuelson and Solow in which they refer to the Phillips curve as "reversible” as “downplay[ing] the possibility

\footnotetext{
${ }^{9}$ JSTOR searches conducted 15 May 2014.
} 
of an unstable Phillips curve.” Samuelson and Solow (1960, p. 189) had already discussed reversibility in their article, by which they seem to mean whether a relationship is stable enough that policy might move the economy along the menu without shifting it too much or destroying it. This discussion appears in the midst of the discussion of the instability of the unemployment/wage-inflation relationship that Hall and Hart essentially ignore. In fact, Samuelson and Solow are modest. With respect to the quantification of the price-Phillips curve, they caution "these are simply our best guesses," and they immediately point out that their curve may provide a reversible menu only in the short run:

All of our discussion has been phrased in short-run terms, dealing with what might happen in the next few years. It would be wrong, though, to think that our Figure 2 menu that relates obtainable price and unemployment behavior will maintain its same shape in the longer run. What we do in a policy way during the next few years might cause [the pricePhillips curve] to shift in a definite way. [Samuelson and Solow 1960, p. 193]

One mechanism that they consider anticipates Phelps and Friedman:

after they had produced a low-pressure economy, the believers in demand-pull might be disappointed in the short run; i.e., prices might continue to rise even though unemployment was considerable. Nevertheless, it might be that the low-pressure demand would so act upon wage and other expectations as to shift the curve downward in the longer run- so that over a decade, the economy might enjoy higher employment with price stability than our present-day estimate would indicate. [p. 193]

And they say that the biggest question not addressed in their article is whether institutional or policy arrangements can shift the Phillips curve downward to the left. Far from downplaying the possibility of an unstable curve, Samuelson and Solow indicate that policies that shift the curve to a more favorable tradeoff might be particularly desirable.

\section{A Want of Intellectual Charity}

The best history and the best criticism require a charitable reading of the subjects under study. It is essential to see exactly what they were trying to do and to attribute to them reasonable and 
defensible choices wherever that is possible. One should make the best case for the subjects under study, and in that way one can sometimes make a much stronger case for where they really went wrong and sometimes, against initial expectation, see that they did not go wrong after all. In offering estimates that combine the data of the 1930s and early 1940s with postwar data, attributing a stability to the data that was never claimed and, indeed warned against; in employing a functional form that necessarily does not have the properties of the hyperbola; in ignoring the central discussion of unemployment and wage-inflation; in failing to try to understand how that discussion is related to the construction of the price-Phillips curve; in treating "estimated" as if it could mean only estimated by regression methods; and in assuming that the specification of the period of twenty-five years was open to only one reasonable interpretation, Hall and Hart have not only failed to give Samuelson and Solow a charitable reading, they have also absurdly attributed a notion of a stable Phillips curve over a period for which Samuelson and Solow explicitly deny that such a stable curve exists. The price paid is simply that they have failed to understand either Samuelson and Solow's point or its historical importance. Samuelson and Solow's article is a tour d'force of back-of-the-envelope economics. It was an exploration, not a destination; an invitation to further research, not a report of a careful study; a suggestion of a possibility for policy guidance, not a blueprint for actual policymakers. Their conclusions were put modestly. The history of the exploration of the Phillips curve in the 1960s and, especially, after the popularization of the expectations-augmented Phillips curve in the wake of Friedman's presidential address demonstrated that the potential of Samuelson and Solow’s article as a catalyst for important research was largely realized. 


\section{Appendix. The Data}

Only two data series are actually deployed explicitly in Samuelson and Solow's paper: “average hourly earnings in manufacturing, including supplements,” which they refer to as Rees’s data (p. 187) and the unemployment rate. Rees (1959, Table 1, pp. 15-16) presents this data, as well as data for labor productivity (with a gap in coverage for the years 1890-1898) for the period 18891957. Samuelson and Solow do not specify a source for the unemployment data, but Hall and Hart (2012, p. 64) say that Solow recollects that Lebergott's unemployment series was spliced to the series from the Bureau of Labor Statistics. The data in Lebergott (1957) run 1900-1954.

Hall and Hart, as we have noted, ignore the wage data, and they say that they take the price and unemployment data that they use from the Economic Report of the President (Eisenhower 1959), noting that it was available to Samuelson and Solow. They assume that, because 1958 was the last full year before Samuelson and Solow wrote their paper, only data up to 1958 would have been used in their study. This is, I believe, an incorrect conclusion. It is true that Samuelson and Solow wrote their paper for presentation on 28 December 1959. It was, however, not published until May 1960. The Economic Report of the President (Eisenhower 1960), in fact contains unemployment data through 1959, and was published on 20 January 1960. They would, therefore, have had an opportunity to update the data through 1959 when revising the paper for publication.

There is a stronger reason to believe that Samuelson and Solow did use data through 1959. Their Figure 1 circles thirteen data points, which it says are from “recent years.” Mapping those points onto the actual data shows that they do not include 1945 or 1946, but do have points that correspond to all the dates from the eleven years 1947-1957. The additional two points 
appear to correspond to 1958 and 1959 once a choice has been made for unemployment rates for those years.

The problem of choice of unemployment rates arises because the Economic Report of the President presents two series - one on old and one on new definitions for unemployment rates. The old series agrees with the Lebergott series. What is more, Samuelson and Solow say that the unemployment rate for 1953 is 2.5 percent, which is the value for the old series - the value for the new series is 2.9 percent. They also say that the value for 1958 is 6.2 percent. But where did they get that number? The old series stops in 1957 and the value for the new series is 6.8 percent. Solow (2014) confirms that they interpolated the missing old series values from the relationship of the old to the new series, which starts in 1947. My own interpolation using a regression of the old series on the new series yields a value of 6.3 for unemployment in 1958 . Hall and Hart use the data from the old series until 1946 and, incorrectly, data from the new series from $1947-1958 .^{10}$

A question arises as to which years are reflected in Samuelson and Solow’s Figure 1. Hall and Hart (2012, p. 70, note 16) say that it reflects 50 or 60 years. But a careful count of the points on the scatterplot show that they number 67 . If the data end in 1959, then the period covered would be 1893-1959. This span does not have the virtue of starting as early as the Rees data (1890, allowing for the loss of one year to calculate growth rates) or for starting as late as 1900, dictated by the coverage of the Lebergott data. One possibility is that they really did start in 1893. Another possibility is that they omitted two data points by mistake - something easily done on a graph obviously constructed by hand. A third possibility would be that two of the points were so close to two other points that they failed to show distinctly. Something like this happens on our Figure 1 in which the points for 1955 and 1957 are so close that the circles are

\footnotetext{
${ }^{10} \mathrm{~A}$ fact determined by comparing data that they sent to me privately for the series that they call ublsnew.
} 
not distinct and what are actually fourteen circled points (1946-1959) appear to be thirteen. It is conceivable that careful measurement of the positions of the points on Samuelson and Solow's Figure 1 might allow us to definitely say which dates are represented there, but it hardly seems an exercise that would repay the trouble. None of the issues raised in this or Hall and Hart's paper would be resolved on that basis.

The actual data used in this paper can be downloaded from:

http://public.econ.duke.edu/ kdh9/Source\%20Materials/Research/SSData-Documentation.xlsx

The data run 1890 to 1959 with wage and productivity data converted to growth rates, and the basic data is defined as follows:

\section{Labor Productivity}

Output per Man-hour, Manufacturing

Units : index 1929=100;

Source: 1889-1957 (with lacunae 1890-1898): Rees (1959), column 6.

\section{Prices}

Consumer Price Index

Units: index 1957=100;

Source: 1889-1957: Rees (1959), column 4;

1958-1959: Eisenhower (1960), Table D-38 (index 1947-1949 = 100 converted to $1957=100)$.

\section{Wage Rate}

Total Compensation (including Wage Supplements)

Units: dollars per hour;

Source: 1889-1957: Rees (1959, Table 1, column 3);

1958-1959: Eisenhower (1960), Table D-24 adjusted as follows:

Compensation_Rees $=1.1584$ Compensation_Eisenhower +0.0283

\section{Unemployment Rate}

Civilian Labor Force Unemployed as a Percentage of the Civilian Labor Force

Units: percent;

Source: 1890-1899: Sutch and Carter (2014), Table Ba470;

1900-1928 Department of Commerce (1960), Series D47;

1929-1957: Eisenhower (1960), Table D17, old definitions;

1958-1959: Eisenhower (1960), Table D17, new definitions, adjusted as follows:

Unemployment_old $=0.9712$ Unemployment_new -0.2597

(Note: these series agree with, or are based on the methods of, Lebergott 1957.) 


\section{References}

Bronfenbrenner, Martin. (1957) “Secular Inflation and Shibboleths,” Challenge 6(3), 17-22.

Department of Commerce, U.S. (1960) Historical statistics of the United States, colonial times to 1957; a Statistical abstract supplement. Washington: Government Printing Office, 1960.

Eisenhower, Dwight D. (1959) Economic Report of the President. Washington, D.C.: United States Government Printing Office.

Eisenhower, Dwight D. (1960) Economic Report of the President. Washington, D.C.: United States Government Printing Office.

Fisher, Irving. (1926) “A Statistical Relation between Unemployment and Price Changes,” International Labour Review, 13(6), 785-92. Reprinted "I Discovered the Phillips Curve: A Statistical Relation between Unemployment and Price Changes," Journal of Political Economy, 81(2, Part 1), pp. 496-502.

Forder, James. (2010a) "Economists on Samuelson and Solow on the Phillips Curve,” University of Oxford, Department of Economics, Economics Series Working Papers: 516.

Forder, James. (2010b) “Friedman's Nobel Lecture and the Phillips Curve Myth,” Journal of the History of Economic Thought 32(3), 329-348.

Forder, James (forthcoming) Macroeconomics and the Phillips Curve Myth. Oxford: Oxford University Press.

Friedman, Milton. (1968) “The Role of Monetary Policy,” American Economic Review 58(1), 117.

Hall, Thomas E. and William R. Hart. (2012) “The Samuelson-Solow Phillips Curve and the Great Inflation,” History of Economics Review 55(1), 62-72.

Humphrey, Thomas M. (1985) “The Early History of the Phillips Curve,” Federal Reserve Bank of Richmond Economic Review 71(5), 17-24.

Humphrey, Thomas M. (1986) “Of Hume, Thornton, the Quantity Theory, and the Phillips Curve,” in Essays on Inflation, $5^{\text {th }}$ ed. Richmond: Federal Reserve Bank of Richmond pp. 128-33.

Kennedy, John F. (1962) Economic Report of the President. Washington, D.C.: United States Government Printing Office.

Keynes, John Maynard. (1936) The General Theory of Employment, Interest, and Money. London: Macmillan.

Leeson, Robert. (1997a) “The Tradeoff Interpretation of Phillips’ Dynamic Stabilization Exercise,” Economica N.S. 64(253), 155-171.

Leeson, Robert. (1997b) “The Political Economy of the Inflation-Unemployment Tradeoff,” History of Political Economy 29(1), 117-156.

Leeson, Robert. (1997c) “The Eclipse of the Goal of Zero Inflation,” History of Political Economy 29(3), 445-496. 
Lipsey, Richard G. (1960) Letter to Robert M. Solow. Solow Papers, Rubenstein Library, Box 57, Folder J-M.

Phelps, Edmund S. "Phillips Curves, Expectations of Inflation and Optimal Unemployment over Time,’ Economica N.S. 34(135), 254-281.

Phillips. A. W. H. (1958) "The Relation between Unemployment and the Rate of Change of Money Wage Rates in the United Kingdom, 1861-1957,” Economica, N.S. 25(100), 283-299.

Rees, Albert (1959) "Patterns of wages, prices, and productivity," in The American Assembly, Columbia University, Wages, Prices, Profits and Productivity: Background Papers and Final Report of the Fifteenth American Assembly, Arden House, Harriman Campus of Columbia University, Harriman, New York April 30-May 3, 1959. Harriman, New York: The American Assembly, Columbia University, 1959, ch. 1, pp. 11-35.

Samuelson, Paul A. and Robert M. Solow. (1960) “Analytical Aspects of Anti-Inflation Policy,” American Economic Review 50(2), 177-194.

Solow, Robert M. (1960) Letter to Richard Lipsey, 21 March 1960. Solow Papers, Rubenstein Library, Box 57, Folder J-M.

Solow, Robert M. (2014) Letter to Kevin D. Hoover, 3 June 2014. Private communication.

Sutch, Richard and Susan B. Carter, editors. (2014) Historical Statistics of the United States. Millennial Edition Online . Cambridge University Press; downloaded 4/30/14. 


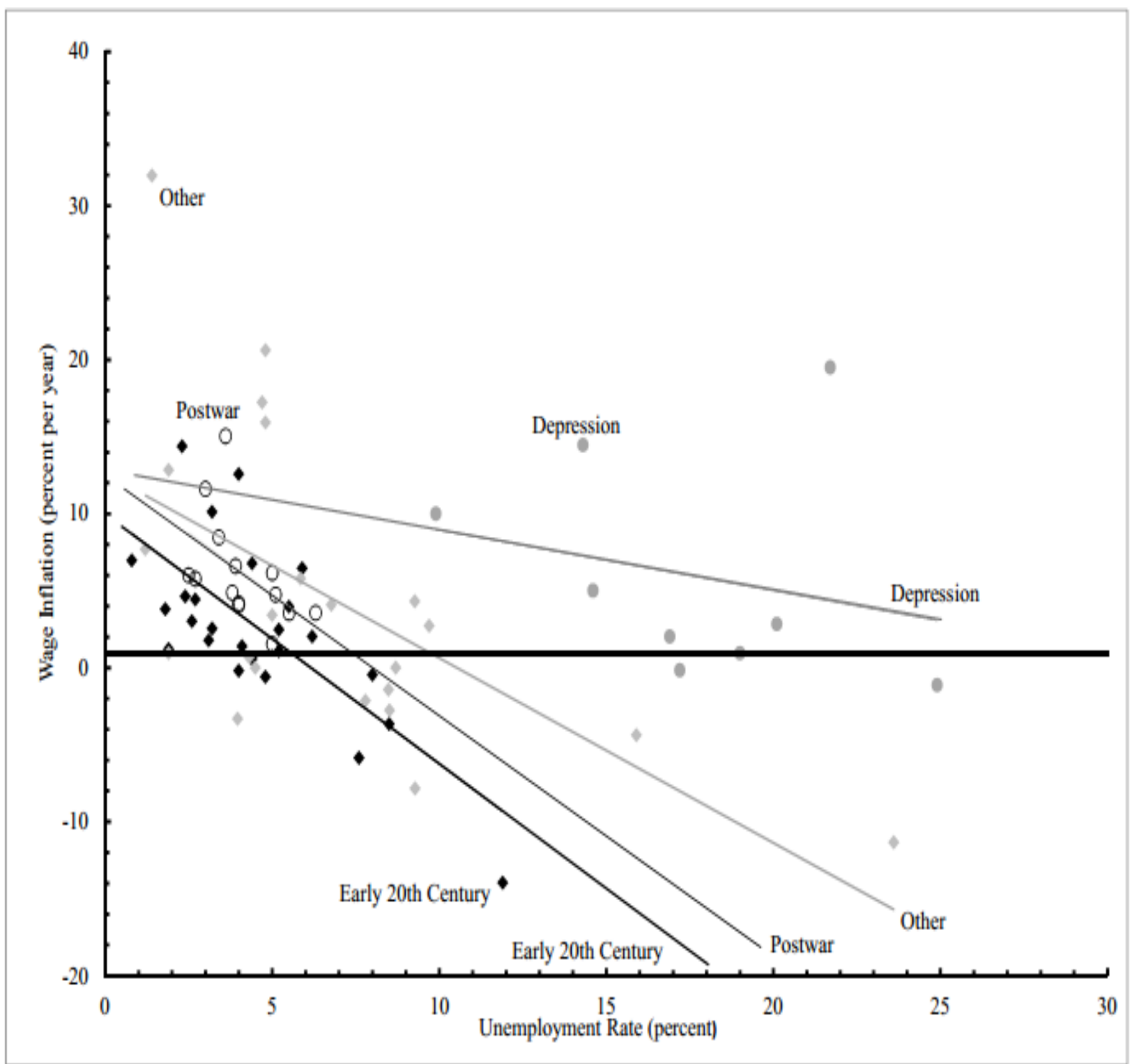

Figure 1. Unemployment and Wage Inflation 1890-1959.

Data and regression lines for four periods: Early $20^{\text {th }}$ Century (1901-1914; 1919-1929);

Depression (1933-1941); Postwar (1946-1959); Other (1890-1900; 1915-1918; 1930-1932)

Source: see Appendix. 


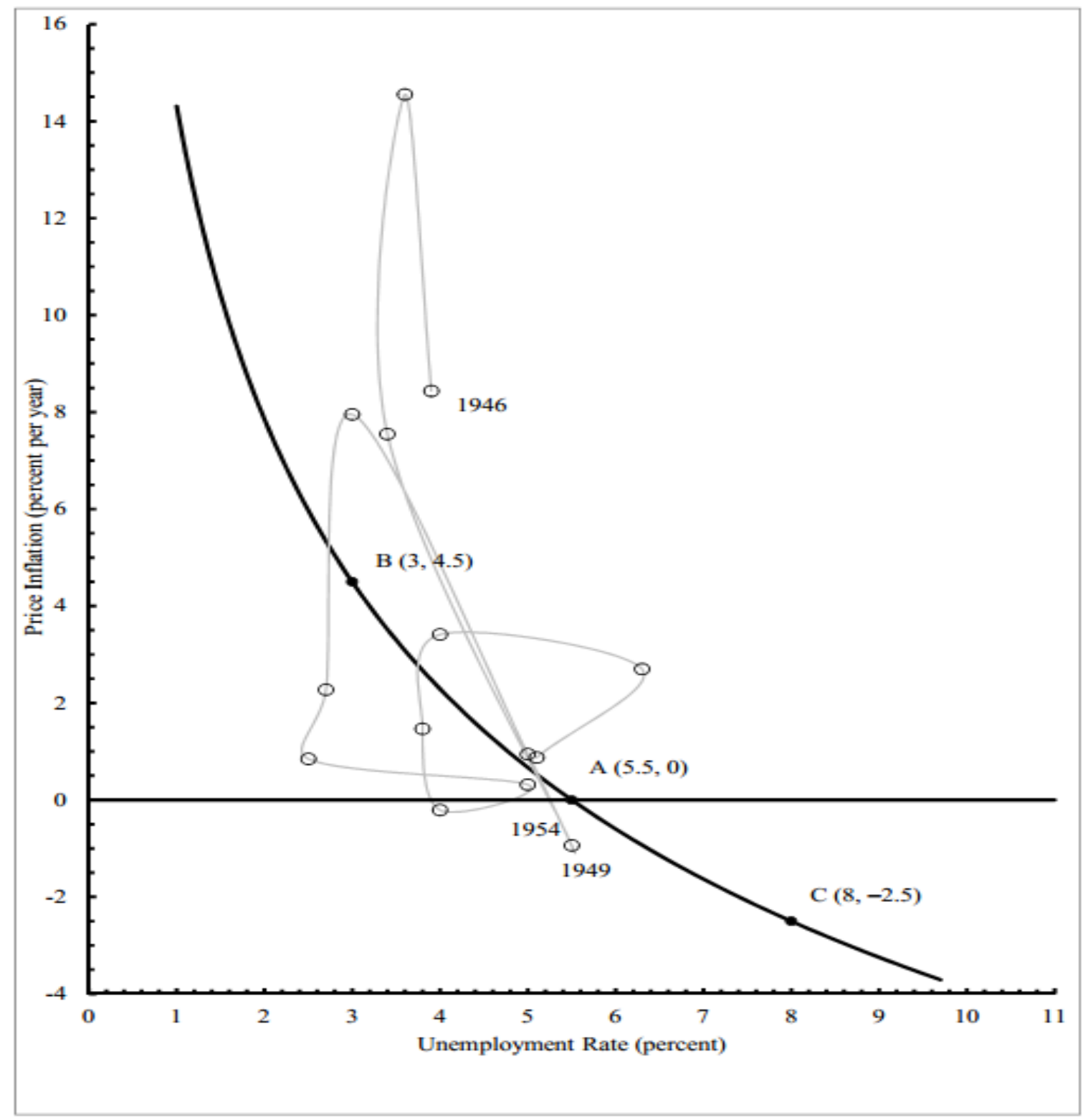

Figure 2. Samuelson and Solow's Price-Phillips Curve and Unemployment/CPI Price Inflation Data for the Postwar Period. Source: see Appendix. 